\title{
Neural tree for estimating the uniaxial compressive strength of rock materials
}

Conference or Workshop Item

Accepted Version

Ojha, V. ORCID: https://orcid.org/0000-0002-9256-1192 and Amban Mishra, D. (2018) Neural tree for estimating the uniaxial compressive strength of rock materials. In: International Conference on Hybrid Intelligent Systems, pp. 110. doi: https://doi.org/10.1007/978-3-319-76351-4_1 Available at https://centaur.reading.ac.uk/93553/

It is advisable to refer to the publisher's version if you intend to cite from the work. See Guidance on citing.

To link to this article DOI: http://dx.doi.org/10.1007/978-3-319-76351-4_1

Publisher: Springer International Publishing

All outputs in CentAUR are protected by Intellectual Property Rights law, including copyright law. Copyright and IPR is retained by the creators or other copyright holders. Terms and conditions for use of this material are defined in the End User Agreement.

\section{www.reading.ac.uk/centaur}

\section{CentAUR}

Central Archive at the University of Reading 
Reading's research outputs online 


\title{
Neural Tree based Predictor for Estimating the Uniaxial Compressive Strength of Rock Materials
}

\author{
Deepak Amban Mishra ${ }^{1,2}$ and Varun Kumar Ojha ${ }^{3,4}$ \\ ${ }^{1}$ Institute of Geonics of CAS, Ostrava, Czech Republic \\ ${ }^{2}$ Indian Institute of Petroleum \& Energy, Visakhapatnam, India \\ ${ }^{3}$ ETH Zurich, Switzerland \\ ${ }^{4}$ Jadavpur University, Kolkata, India
}

\begin{abstract}
Uniaxial Compressive Strength (UCS) is the most important parameter that quantifies the rock strength. However, determination of the UCS in the laboratory is very expensive and time-consuming. Therefore, common index tests like point load (Is-50), ultrasonic velocity test ( $\mathrm{V}_{\mathrm{P}}$ ), block punch index (BPI) test, rebound hardness (SRH) test, physical properties, etc., have been used to predict the UCS. All these properties can be determined in both fields as well as in the laboratory. The computational intelligence methods are promising techniques, which have proven to be very reliable in the recent years. Hence, the objective of this work is to develop a predictive model using a multiobjective heterogeneous flexible neural tree $\left(\mathrm{HFNT}^{\mathrm{M}}\right)$ that can estimate the UCS with high accuracy and assess the effectiveness of different index tests in predicting the UCS of rock materials. UCS and indices such as BPI, Is-50, SRH, VP, effective porosity and density were determined for the granite, schist, and sandstone. The predictive performance of the developed $\mathrm{HFNT}^{\mathrm{M}}$ model was examined through correlation coefficient, coefficient of determination, and RMSE. On the basis of statistical parameters, it can be said that the constructed model efficiently predicted the UCS based on the knowledge gathered from the experimental data in a very quick time ( 9 seconds). The developed HFNT ${ }^{\mathrm{M}}$ model was also used to assess the effectiveness of different index tests in predicting UCS with the help of feature selection rate $R$ and predictability score $P$. From $R$ and $P$ values of the individual index test results, it is found that destructive mechanical rock indices BPI and Is-50 are the best index tests to estimate the UCS.
\end{abstract}

Keywords: Uniaxial compressive strength; index tests; rock materials; heterogeneous flexible neural tree; feature analysis.

\section{Introduction}

Uniaxial compressive strength (UCS) is the most familiar parameters used in rock engineering projects. In rock mass rating (RMR), proposed by Bieniawski [1], UCS is the only parameter to assess the strength of rock material. However, high quality machined specimens are required for determining UCS in the laboratory [2-3]. This makes the test expensive and time-consuming. Therefore, different empirical predictive models are being used to estimate the UCS of rock materials indirectly from the index tests, which require little or no specimen preparation and are less expensive than the uniaxial compression test. Amongst different predictive models, regression analyses are the most commonly used. Lists of such relationships between the index tests and UCS obtained by different researchers have been given in [20].

In the last decade, however, the use of computational intelligence (CI) methods to establish predictive models has gained much interest in the areas of rock mechanics. A comprehensive list of such works are presented in Table 1 . These research works indicate the requirement of improvement in the CI methods to estimate UCS from the index test results and to assess the effectiveness of individual index tests for predicting the UCS of rock materials. 
Although several predictive models have been proposed to estimate the UCS from index tests, the influence of various index tests in predicting UCS is not entirely understood. More specifically, so far, to the best of our literature survey, no study has been done on assessing the effectiveness of different index tests. Moreover, it is always advantageous if development time and effort of the predictive modeling can be reduced. To achieve these goals, the use of the neural network (NN) or similar CI methods on a limited set of experimental data for predictive modeling can be a great benefit. Hence, the aim of this work is to develop a predictive model that can estimate the UCS with a high accuracy and assess the effectiveness of different index tests in predicting UCS of rock materials.

The multiobjective heterogeneous flexible neural tree $\left(\mathrm{HFNT}^{\mathrm{M}}\right)$ produces a tree-like model, where the nodes of the tree are similar to the NN nodes was used in this study [7]. Interestingly, HFNT ${ }^{\mathrm{M}}$ differs from NN [4] in its structural configuration, and it differs from the commonly used regression tree [5] in its node type. Moreover, the tree-like structure in the $\mathrm{HFNT}^{\mathrm{M}}$ is created by using multiobjective genetic programming (MOGP) [6-7]. Therefore, the primary advantages of using $\mathrm{HFNT}^{\mathrm{M}}$ over other CI techniques lie in its ability of the automatic adaptation into the structure and the input feature selection.

Such an ability like HFNT ${ }^{\mathrm{M}}$ is necessary and has been successfully used in several real life applications [32]. However, this method has not been exploited in estimating the UCS from index tests. In this work, index tests namely block punch index (BPI), point load strength (Is-50), Schmidt rebound hardness (SRH), ultrasonic P-wave velocity $\left.\left(\mathrm{V}_{\mathrm{P}}\right)\right]$, and physical properties namely effective porosity $\left(\eta_{\mathrm{e}}\right)$ and density $\left.(\rho)\right]$ are determined and used for estimating the UCS of granite, schist, and sandstone. An improved CI technique, $\mathrm{HFNT}^{\mathrm{M}}$, was employed for this purpose and it was used to determine the effectiveness of index tests BPI, Is-50, SRH, Vp, $\eta_{e}$, and $\rho$ in the prediction of UCS of three rocks. Such kind of individual test effectiveness assessment using HFNT ${ }^{\mathrm{M}}$ has not been studied in the past, and it is the noble contribution of this research along with the predictive modeling. The evaluation of individual tests provides a detailed insight of UCS prediction of rock materials.

\section{Materials and Methodology}

Three completely different rock types, granite, schist, and sandstone were consciously investigated in the laboratory to capture a broad scenario in evaluating UCS. Core samples of granite, schist, and sandstone were collected from Malanjkhand Copper Project Malanjkhand; UCIL mine at Jaduguda; and SCCL, Kothagudem respectively. Each core sample (20 from each rock type) was cut into four pieces as required for uniaxial compression, point load, block punch, and Schmidt rebound hardness tests (as per [2-3]). Results of the entire laboratory investigation were taken from [25]. During the point load and block punch tests, few granite and sandstone specimens failed in invalid failure modes. For these specimens, BPI and Is-50 were indirectly calculated using simple regression equations (developed from same rock types of the same locality as this study) presented in [20]. A total 60 samples (20 from each rock types) were used for the predictive modeling.

\section{Predictive Models}

\subsection{Computational Intelligence Techniques}

Discovering knowledge contained in data and developing predictive models are vital tasks performed by the CI methods. Moreover, predictive modeling identifies the underlying relationship between an input variable $\boldsymbol{X}=\left\{\mathbf{x}_{1}, \mathbf{x}_{2}, \ldots, \mathbf{x}_{\mathrm{N}}\right\}$ and an output variable $\boldsymbol{d}=\left\{d_{1}, d_{2}, \ldots, d_{N}\right\}$ through the learning parameter $\mathbf{w}$, which defines the said relationship. A CI method finds the learning parameter $\mathbf{w}$ by usually reducing the root mean square error (RMSE) $e$ between the predicted output $\boldsymbol{y}=\left\{y_{1}, y_{2}, \ldots, y_{N}\right\}$ and the desired output $\boldsymbol{d}$. Hence, the learning of a CI method indicate the search for a proper learning parameter $\mathbf{w}$. In this study, the RMSE was evaluated as: 
Table 1: Previous studies on the use of computational intelligence techniques in estimating UCS and other rock engineering parameters from index tests.

\begin{tabular}{|c|c|c|c|c|c|}
\hline Ref. & Rock Types & Inputs & Output/s & CI model/s & $r / r^{2}$ \\
\hline [8] & $\begin{array}{l}\text { Sandstone; } \\
\text { Granodiorite }\end{array}$ & $\begin{array}{l}\text { Equotip Hardness; Density; } \\
\text { Porosty; Grain size }\end{array}$ & UCS & ANN & $r=0.96$ \\
\hline [9] & $\begin{array}{l}\text { Sandstone; Limestone; } \\
\text { Dolomite; Granite; } \\
\text { Granodiorite }\end{array}$ & $\begin{array}{l}\text { Equotip Hardness; } \\
\text { Density; Porosity }\end{array}$ & UCS & FIS (TSK) & \\
\hline [10] & $\begin{array}{l}\text { Quartzite schist; Chlorite } \\
\text { Schist; Quartz mica } \\
\text { schist; Biotite schist }\end{array}$ & $\begin{array}{l}\text { Mineral composition; Grain size; } \\
\text { Area weighing; Aspect ratio } \\
\text { Form factor; orientation }\end{array}$ & $\begin{array}{l}\text { UCS; Tensile strength; } \\
\text { Is(50) }\end{array}$ & ANN & $r=0.76$ \\
\hline [11] & Greywacke & $\begin{array}{l}\text { VP; Is-50; BPI; } \\
\text { Tensile strength }\end{array}$ & UCS; Elastic Modulus & $\begin{array}{l}\text { FIS } \\
\text { (Mamdani) }\end{array}$ & $r=0.8$ \\
\hline [12] & Sandstone & $\begin{array}{l}\text { Compressive strength; Density; } \\
\text { SRH; Quartz \%; Feldspar \%; } \\
\text { Iron oxide \% }\end{array}$ & P-wave velocity & ANN & $r^{2}=0.94$ \\
\hline [13] & $\begin{array}{l}\text { Greywacke; } \\
\text { Agglomerate }\end{array}$ & UCS; Unit weight & Elastic Modulus & ANN & $r=0.82$ \\
\hline [14] & $\begin{array}{l}\text { Sandstone; Limestone; } \\
\text { Coal; Mudstone; Grit }\end{array}$ & $\begin{array}{l}\text { Cone indenter hardness; Shore } \\
\text { hardness; dry density }\end{array}$ & UCS; Elastic Modulus & ANN & $r=0.71$ \\
\hline [15] & Sandstone & $\begin{array}{l}\text { Packing Density; Concavity- } \\
\text { convexity; Quartz \% }\end{array}$ & UCS & ANN & $r=0.87$ \\
\hline [16] & Granite & Porosity; VP; UCS & Weathering grade & $\begin{array}{l}\text { ANN, } \\
\text { FIS }\end{array}$ & $\begin{array}{l}r=0.96 \\
r=0.93\end{array}$ \\
\hline [17] & Gypsum & Water content; Is-50; VP & UCS; Elastic Modulus & $\begin{array}{l}\text { ANN } \\
\text { ANFIS }\end{array}$ & $\begin{array}{l}r^{2}=0.88 \\
r^{2}=0.94\end{array}$ \\
\hline [18] & Travertine & VP; Is-50; SRH; Porosity & UCS; Elastic Modulus & ANN & $r^{2}=0.64$ \\
\hline [19] & $\begin{array}{l}\text { Sandstone; Shale; } \\
\text { Limestone }\end{array}$ & $\begin{array}{l}\text { Total porosity; Bulk density; } \\
\text { Water saturation }\end{array}$ & UCS & ANN & $r=0.91$ \\
\hline [20] & $\begin{array}{l}\text { Granite; Schist; } \\
\text { Sandstone }\end{array}$ & BPI; Is-50; SRH; VP & UCS & $\begin{array}{l}\text { FIS } \\
\text { (Mamdani) }\end{array}$ & $r=0.99$ \\
\hline [21] & Granite & $\begin{array}{l}\text { Tensile strength; BPI; } \\
\text { Is(50); VP }\end{array}$ & UCS & $\begin{array}{l}\text { ANN } \\
\text { ANFIS }\end{array}$ & $\begin{array}{l}r=0.6 \\
r=0.69\end{array}$ \\
\hline [22] & Granite & $\begin{array}{l}\text { Quartz \%; Plagioclase \%; } \\
\text { Orthoclase \% }\end{array}$ & UCS & ANFIS & $r=0.87$ \\
\hline [23] & Shale & $\begin{array}{l}\text { Dry density; Is-50; BTS; VP; } \\
\text { SRH }\end{array}$ & $\begin{array}{l}\text { Internal friction angle; } \\
\text { interlocking }\end{array}$ & PSO-ANN & $r=0.94$ \\
\hline [24] & Granite & $\begin{array}{l}\text { Dry density, VP; Qtz content; } \\
\text { Plg content }\end{array}$ & UCS; Elastic Modulus & $\begin{array}{l}\text { MRA } \\
\text { ANN }\end{array}$ & $\begin{array}{l}r=0.54 \\
r=0.91\end{array}$ \\
\hline [25] & $\begin{array}{l}\text { Granite; Schist; } \\
\text { Sandstone }\end{array}$ & BPI; Is-50; SRH; VP & UCS & $\begin{array}{l}\text { FIS (TSK) } \\
\text { ANN }\end{array}$ & $\begin{aligned} r & =0.98 \\
r & =0.94\end{aligned}$ \\
\hline
\end{tabular}

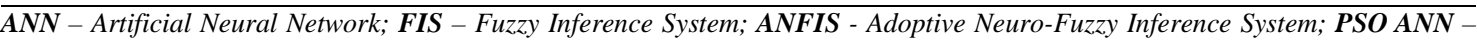
Particle Swamp Optimization based Artificial Neural Network; RT - Regression trees; BPI - Block Punch Index; Is-50 - Pointload Strength; $\boldsymbol{S R H}$ - Rebound Hardness; $\boldsymbol{V}_{\boldsymbol{P}}$ - Ultrasonic P-wave Velocity. 


$$
e=\sqrt{\frac{1}{N} \sum_{i=1}^{N}\left(y_{i}-d_{i}\right)^{2}}
$$

where $N$ denotes the total training/test samples. Additionally, correlation coefficient $r$ was also used in this study. The correlation coefficient $r$ computes the correlation between the predicted output $\boldsymbol{y}$ and the desired output $\boldsymbol{d}$, which is written as:

$$
r=\frac{\sum_{i=1}^{N}\left(y_{i}-\overline{\mathbf{y}}\right)\left(d_{i}-\overline{\boldsymbol{d}}\right)}{\sqrt{\sum_{i=1}^{N}\left(y_{i}-\overline{\mathrm{y}}\right)^{2} \sum_{i=1}^{N}\left(d_{i}-\overline{\boldsymbol{d}}\right)^{2}}}
$$

where $\overline{\boldsymbol{y}}$ and $\overline{\boldsymbol{d}}$ are the average of predicted and desired outputs. The correlation coefficient ranges from -1 to 1 , where a value 1 indicates strongest correlation (the best performance).

In this study, CI methods such as fuzzy inference system (FIS), multilayer perceptron (MLP), and adaptive neuro-fuzzy inference system (ANFIS) were considered apart from the proposed HFNT $^{\mathrm{M}}$. The FIS, MLP, and ANFIS are most widely used CI methods for modeling industrial and engineering problems [26]. The brief introduction to the mentioned CI methods are as follow:

- An FIS is a rule-based system, where a set of IF-THEN rules are designed from the given input variables. Subsequently, the rules are inferred (conclusion drawn from the rules set) to predict the output of the system for any given input [27].

- An MLP is an NN model, which is an imitation of human-like learning. An MLP is layered network of neural nodes (computational node) arranged in a layered structure. The nodes in an MLP are connected with synaptic links. The primary form of MLP training for a given dataset is the discovery of appropriate values for the synaptic links [4].

- An ANFIS is a combination both FIS and NN-based systems, where an FIS is designed as an NNlike model. ANFIS is typically a six-layered system in which the layers indicate the IF and THEN parts of an FIS [28].

\subsection{Multiobjective Heterogeneous Flexible Neural Tree (HFNT ${ }^{\mathrm{M}}$ )}

An HFNT $^{\mathrm{M}}$ similar to any other CI methods tries to minimize the error $e$ (often RMSE is used) for the given dataset by optimizing its parameter using some learning algorithms (HFNT ${ }^{\mathrm{M}}$ employ multiobjective genetic programming and differential evolution for this purpose). The structure of HFNT $^{\mathrm{M}}$ is a tree-like that has internal nodes as the computational nodes (analogous to MLP neurons), branches (similar to MLP synaptic links), and leaf nodes (to represent input variables).

Mathematically, an HFNT ${ }^{\mathrm{M}}$, denoted as $G$, is a union of internal node $V$ and the leaf node $T$. The internal node $V$ is a set of internal (computational) nodes and, the leaf node $T$ is a set of inputs [7]. Hence, an HFNT $^{\mathrm{M}} G$ can be expressed as:

$$
G=V \cup T=\left\{v_{2}^{U(k)}, v_{3}^{U(k)}, \ldots, v_{t n}^{U(k)}\right\} \cup\left\{x_{1}, x_{2}, \ldots, x_{d}\right\}
$$

where $v_{i}^{U(k)}(i \in\{2,3, \ldots, t n\})$ indicates an internal (computational) node that takes two or more arguments; whereas, the leaf node takes no argument. The function $U(k)$ randomly invoke an activation function at a computational node from a set of activation function. In this study, the set of activation functions contained Gaussian, tangent hyperbolic, bipolar sigmoidal, unipolar sigmoidal, and Fermi. HFNT $^{\mathrm{M}}$ training has two aspects. Firstly, discovering appropriate tree structure and secondly, the optimization of tree parameters. These two HFNT $^{\mathrm{M}}$ training parts are performed in two phases:

- $\quad$ Phase 1: Tree structure training using multiobjective genetic programming (MOGP).

- $\quad$ Phase 2: Tree parameter training using differential evolution (DE). 


\subsubsection{Structure Optimization Phase}

Tree structure training of HFNT $^{\mathrm{M}}$ takes place by employing MOGP, which is a population-based evolutionary-inspired algorithm. MOGP iteratively finds a suitable tree-structure through a vast topological search space by applying two operators: crossover and mutation [29]. During the search, MOGP satisfies two objectives: reduction of tree size (model complexity) and reduction of RMSE (approximation error) and hence called multiobjective genetic programming. From a population of trees, two trees are randomly selected for crossover operation, and their selected subtrees are swapped between them. On the contrary, in a mutation operation, one tree is chosen from a population of trees, and its randomly selected subtree is either replaced by another randomly created subtree, or deleted entirely, or some other form of mutation operators can be used:

- $\quad$ Changing one leaf node with a new leaf node;

- Changing all leaf nodes with new leaf nodes;

- Expanding a randomly selected tree by appending a new subtree to it;

- Changing an internal node with a leaf node.

The advantage of employing MOGP, which is an evolutionary algorithm inspired by the dynamics of natural selection that it allows only the best inputs to be selected into the obtained tree structure (inputs with the best prediction ability).

\subsubsection{Parameter Optimization Phase}

The DE is a population-based algorithm applied for optimizing the parameters of a function. Here, it is the parameters of the tree structure. DE employ an evolutionary-inspired operator that iteratively searches through a vast search space to optimize a parameter vector that represents a model/function [30-31].

Given a population $H$ of the tree's parameter vectors, DE attempts to search an optimal parameter vector $\mathbf{h}^{*}$ by employing the operators such as selection, crossover, mutation, and recombination. The selection operator of DE selects three random vectors $\mathbf{r}_{1}, \mathbf{r}_{2}$, and $\mathbf{r}_{3}$ from the population $H$ such that $\mathbf{r}_{1} \neq \mathbf{r}_{2} \neq \mathbf{r}_{3}$. Additionally, a vector $\mathbf{g}$ indicating the best solution in the population $H$ is selected. Thereafter, a new parameter vector $\mathbf{h}^{\text {new }}$ is created as:

$$
\mathbf{h}^{\text {new }}= \begin{cases}\mathbf{r}_{1}+\mathrm{F} \times\left(\mathbf{r}_{1}-\mathbf{g}\right)+\mathrm{F} \times\left(\mathbf{r}_{2}-\mathbf{r}_{3}\right), & \text { if } \quad \mathbf{u}<\mathrm{C} \\ \mathbf{r}_{1}, & \text { if } \quad \mathbf{u} \geq \mathrm{C}\end{cases}
$$

where $\mathbf{u}$ is a random vector uniformly distribution between 0 and $1, \mathrm{C}$ is the crossover probability, and $\mathrm{F}$ is the mutation factor. Eq. (4) is the imitation of crossover and mutation operations and the condition $\mathbf{u}<\mathrm{C}$ indicates that the operation will be performed if a random value $u_{i} \in \mathbf{u}$ is less than crossover probability $\mathrm{C}$. This DE iterations is repeated until $\mathbf{h}^{*}$ is found or a maximum iteration reached. A general $\mathrm{HFNT}^{\mathrm{M}}$ optimization algorithm is summarized in Fig. 1 that indicates the mentioned optimization phases.

Predictive modeling for UCS estimation with the HFNT ${ }^{\mathrm{M}}$ and other CI methods was performed as follow: Firstly, the obtained dataset was randomly partitioned into training (75\%) and test (25\%) sets as it was carried out in [25]. The models were trained for the training samples and the tested for the test samples. Accordingly, the results were collected. For HFNT ${ }^{\mathrm{M}}$, this process was repeated for 20 times (specifically for the feature analysis purpose), and at each time, $75 \%$ training and $25 \%$ test samples were randomly obtained. For other CI methods (i.e., FIS, MLP, and ANFIS), the results were collected from [25].

During HFNT $^{\mathrm{M}}$ training the collected dataset was normalized features-wise by applying a min-max normalization method. Subsequently, for computing the model's output, the obtained output was denormalized. Table 2 lists the underlying parameters chosen during HFNT $^{\mathrm{M}}$ models development. The 
performance of the developed model using the proposed $\mathrm{HFNT}^{\mathrm{M}}$ and other CI methods were evaluated and compared by using the following four performance indicators: RMSE defined as Eq. (1), correlation coefficient $r$ defined as Eq. (2), coefficient of determination $r^{2}$, and the model's complexity (i.e., the total number of parameters in the models).

Table 2: Parameters settings and the values chosen during HFNTM training.

\begin{tabular}{llll}
\hline$\#$ & Parameter Name & Definition/Purpose & Value \\
\hline 1 & Tree height & The maximum levels of a tree. & 5 \\
2 & Tree arity & Maximum siblings of a node in a tree. & 4 \\
3 & Tree node type & Type of activation function used at nodes. & Random \\
4 & GP population & Total candidates in a GP population. & 20 \\
5 & Mutation probability & The frequency of mutation operation. & 0.2 \\
6 & Crossover probability & The frequency of crossover operation. & 0.8 \\
8 & Tournament size & Total candidates for a tournament. & 10 \\
9 & DE population & The initial size of the DE population. & 50 \\
10 & Range of node search & The lower and upper bound of activation function arguments. & {$[0,1]$} \\
11 & Range of edge search & The lower and upper bound of tree edges. & {$[-1.0,1.0]$} \\
13 & Structure training & Maximum generations of GP training. & 100 \\
14 & Parameter training & Maximum evaluations of parameter training. & 1000 \\
15 & Number of objectives & Tree size (complexity) and RMSE & 2 \\
\hline
\end{tabular}

3.3 Input Feature Analysis

Feature analysis was conducted to assess the effectiveness of different index tests in predicting UCS of rock materials. To perform such feature analysis, 20 HFNT $^{\mathrm{M}}$ models were created. Each HFNT ${ }^{\mathrm{M}}$ models provided information selected inputs and models prediction strength (in terms of RMSE). Hence, a list of 20 models with the account of their selected inputs and RMSE was prepared.

To analyze the selected input features and their predictability, two performance indicators feature selection rate $R$ and predictability score $P$ were used [31]. Feature selection rate $R$ is the measure of the total number of times a specific set of input feature was occurred in the prepared list $M=\left[m_{1}, \ldots, m_{20}\right]$ of 20 models. Here, $|M|$ indicating the size of the list was 20 . Therefore, the input-feature selection rate is computed as:

$$
R_{j}=\frac{1}{|M|} \sum_{i=1}^{|M|} \mathbb{I}\left(m_{i}=A_{j}\right)
$$

where $R_{j}$ is the selection rate of $j$-th input feature set $A_{j} \in \mathcal{P}\left(\left\{\mathrm{BPI}, \mathrm{Is}-50, \mathrm{SRH}, \mathrm{V}_{P}, \eta_{e}, \rho\right\}\right)$, and function $\mathbb{I}\left(m_{i}=A_{j}\right)$ is a function that returns "1" if $j$-th input-feature set $A_{j}$ is selected by the $i$-th model $m_{i}$, otherwise, it returns " 0 ." Feature selection rate $R_{j}=1$ is the highest (i.e., all the models selected the inputfeature set $A_{j}$ ) and $R_{j}=0$ is the lowest (i.e., no model selected the input-feature set $A_{j}$ ).

The predictability score $P_{j}$ of an input feature set $A_{j}$ is on the other hand is necessary to determine along with the selection rate $R_{j}$ because the models in the list may not be equal in their performances. To determine the predictability score $P_{j}$ of $j$-th input-feature set $A_{j}$, the performance $F_{j}$ (typically the RMSE) of the corresponding input-feature set $A_{j}$ was at first computed as [31]: 


$$
F_{j}= \begin{cases}\sum_{i=1}^{|M|} e_{i} \times \mathbb{I}\left(m_{i}=A_{j}\right), & \text { if }\left|\mathrm{A}_{\mathrm{j}}\right|=1 \\ \sum_{i=1}^{|M|} e_{i} \times \mathbb{I}\left(m_{i}=A_{j}\right) / \sum_{i=1}^{|M|} \mathbb{I}\left(m_{i}=A_{j}\right), & \text { if }\left|\mathrm{A}_{\mathrm{j}}\right|>1\end{cases}
$$

where $e_{i}$ indicates the RMSE of $i$-th model. The performance $F_{j}$ for $\left|A_{j}\right|=1$ is the sum of RMSEs and $F_{j}$ for $\left|A_{j}\right|>1$ is the average RMSEs of all models that selected a subset $A_{j}$. Accordingly, the predictability score $P_{j}$ corresponding to an input-feature set $A_{j}$ was computed by normalizing the performance as [31]:

$$
P_{j}=\frac{F_{j}}{\max _{j=1}\left(F_{j}\right)}
$$

where function $\max ($.$) evaluate the maximum performance value among all F_{j}$. Analogous to the selection rate $R_{j}$, the predictability score $P_{j}=1$ for an input-feature set $A_{j}$ describes the heights impact on the model's predictability and the score $P_{j}=0$ describes the least impact on the model's predictability.

\section{Result and Discussion}

\subsection{Models Prediction}

The developed best model by HFNT ${ }^{\mathrm{M}}$ is shown in Fig. 1, where the leaf nodes indicate the input features and the root node gives the predicted output UCS of the model. UCS values were predicted from BPI, Is$50, \mathrm{SRH}, \mathrm{V}_{\mathrm{P}}, \eta_{\mathrm{e}}$ and $\rho$ (Table 2) by using $\mathrm{HFNT}^{\mathrm{M}}$ model developed in this study. UCS values estimated from the model are plotted against their corresponding experimentally determined UCS values both for training (Fig. 2a) and test (Fig. 2b) data. The predictive performance of the developed model was examined through $e, r, r^{2}$, and complexity. The $e, r, r^{2}$, and complexity obtained in this study was compared with the $e, r, r^{2}$, and complexity obtained from FIS (TSK), MLP and ANFIS models as presented in [25] for the same data set and the results are presented in Table 3.

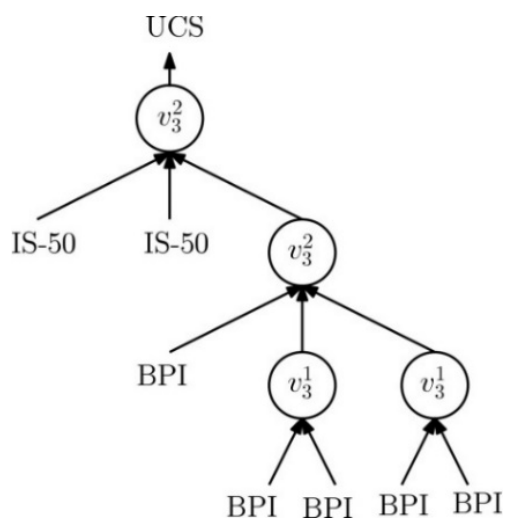

Fig. 1: Developed multiobjective heterogeneous flexible neural tree.

\begin{tabular}{|c|c|c|c|c|c|c|c|}
\hline & \multirow[t]{2}{*}{ FIS $^{\mathbf{a}}$} & \multicolumn{2}{|c|}{$M P^{a}$} & \multicolumn{2}{|c|}{ ANFIS $^{\mathbf{a}}$} & \multicolumn{2}{|c|}{ HFNT $^{\mathrm{M}}$} \\
\hline & & Train & Test & Train & Test & Train $^{c}$ & Test $^{c}$ \\
\hline RMSE & 9.54 & 14.33 & 16.9 & 7.87 & 13.72 & 10.92 & 5.87 \\
\hline$r^{2}$ & 0.97 & 0.92 & 0.89 & 0.98 & 0.94 & 0.97 & 0.99 \\
\hline$r$ & 0.98 & 0.96 & 0.94 & 0.99 & 0.97 & 0.98 & 0.99 \\
\hline Complexity & $5800^{b}$ & 25 & & $44^{\mathrm{b}}$ & & 11 & \\
\hline
\end{tabular}

Table 3: Performance results of the models by statistical analysis for the training and test dataset. 
From the Fig. 2 and Table 3, it can be said that correlation coefficient of the developed HFNT ${ }^{\mathrm{M}}$ model is similar to that of the FIS (TSK), MLP and ANFIS models. However, based on the RMSE of test data, it can be said that the HFNT ${ }^{\mathrm{M}}$ model is better than other models. Besides the statistical parameters, computational time of the developed model was 9 seconds, and the complexity was 11 parameters for such a wide range of data obtained for three completely different rock types. Considering all these factors, RMSE, $r, r^{2}$, and computation time, it can be said the HFNT ${ }^{\mathrm{M}}$ is a very effective tool for determining the UCS from index tests. Additionally, the HFNT ${ }^{\mathrm{M}}$ is a less complex model than the other CI model. As shown in Table 3, the total parameters in the HFNT ${ }^{\mathrm{M}}$ were smaller than the other CI models. Hence, HFNT $^{\mathrm{M}}$ is a better model in both implementation and computational points of view.
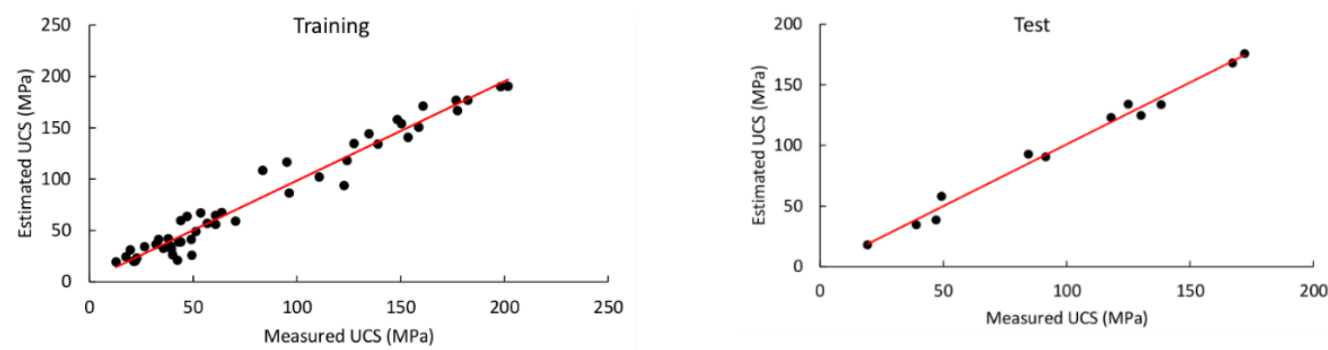

Fig. 2 Estimated UCS plotted against measured UCS: (a) training (b) test.

\subsection{Feature Analysis Results}

A total 20 models were created using $\mathrm{HFNT}^{\mathrm{M}}$ for feature analysis. Since the models were created by employing an evolutionary algorithm, the inputs that contributed most towards UCS prediction were primarily selected. Hence, a list of selected inputs by each model was prepared with the account of their RMSEs. Afterward, a comprehensive feature analysis of all 6 input features was performed. For the input feature analysis, two performance indicators, feature selection rate $R$ as defined in Eq. (5) and feature predictability score $P$ as defined in Eq. (7), were adopted.

The effectiveness of individual index tests BPI, Is-50, SRH, $\mathrm{V}_{\mathrm{P}}, \eta_{\mathrm{e}}$ and $\rho$ in estimating the UCS were examined through $R$ and $P$. Table 4 presents the results of feature analysis carried out for the all 6 individual inputs. The input features BPI and Is-50 represent the destructive mechanical indices; whereas, SRH and $V_{P}$ represent the non-destructive rock indices. Effective porosity $\left(\eta_{e}\right)$ and density $(\rho)$ are the determined physical properties of the concerned rocks. It can be observed that $R$ and $P$ of destructive mechanical indices BPI and Is-50 were much higher than that of $R$ and $P$ values of non-destructive and physical rock indices.

Table 4: Significance of individual input features.

\begin{tabular}{llll}
\hline$\#$ & Input Features & Selection Rate $(\boldsymbol{R})$ & Predictability Score $(\boldsymbol{P})$ \\
\hline 1 & $A_{1}=\{\mathrm{BPI}\}$ & 0.862 & 0.899 \\
2 & $A_{2}=\{\mathrm{Is}-50\}$ & 0.959 & 1 \\
3 & $A_{3}=\{\mathrm{SRH}\}$ & 0.525 & 0.547 \\
4 & $A_{4}=\{\mathrm{VP}\}$ & 0.147 & 0.154 \\
5 & $A_{5}=\{$ ne $\}$ & 0.339 & 0.354 \\
6 & $A_{6}=\{\rho\}$ & 0.574 & 0.599 \\
\hline
\end{tabular}

Among the individual input features, $R$ and $P$ of Is-50 are 0.959 and 1 respectively. Next in the list is BPI with $R$ and $P$ of 0.862 and 0.899 respectively. From the performed feature analysis, it can be said that Is50 is the best index to predict the UCS of rock materials. Since BPI also has significantly high $R$ and $P$, we 
can say that destructive mechanical rock indices are the best proxy for estimating the UCS of the rock material. This finding is also in accordance with the experimental findings of [33].

\section{Conclusions}

The experimental program included the determination UCS, BPI, Is-50, SRH, $\mathrm{V}_{\mathrm{P}}$, porosity and density of three different rock types (granite, schist, and sandstone). To estimate the UCS from the index tests, a multiobjective heterogeneous flexible neural tree $\left(\mathrm{HFNT}^{\mathrm{M}}\right)$ model was proposed. HFNT $^{\mathrm{M}}$ uses learning algorithms like multiobjective genetic programming and differential evolution to adapt its structure and parameters. Such adaptation was carried out by optimizing the constituents of the tree-like structure: internal nodes (computational nodes), branches (weights) and leaf nodes (input nodes). The inputs and outputs for the developed HFNT ${ }^{\mathrm{M}}$ model were used from the experimental results. The constructed model efficiently estimated the UCS based on the information gathered from the experimental data in a very quick time (9 seconds). Additionally, the HFNT ${ }^{\mathrm{M}}$ was a less complex model than the other CI model. Therefore, this model can be effectively used in estimating the UCS. Developed HFNT ${ }^{\mathrm{M}}$ can also assess the effectiveness of different index tests in predicting UCS of rock materials with the help of feature selection rate $R$ and predictability score $P$. From $R$ and $P$ values of the individual input features (index test results), it is found that Is-50 is the best proxy for the UCS. Among the different types of index tests destructive indices, non-destructive indices, and physical properties the destructive mechanical rock indices BPI and Is-50 are found to be the best index tests to estimate the UCS.

\section{References}

[1] Bieniawski ZT (1989) Engineering Rock Mass Classifications. Wiley, New York, p. 251

[2] ISRM (2007) The complete ISRM suggested methods for rock characterization, testing and monitoring. In: Ulusay R, Hudson JA, editors. Suggested Methods Prepared by the Commission of Testing Methods. Kozan Ofset, Ankara: ISRM; 1974-2006. Compilation Arranged by the ISRM Turkish National Group

[3] ASTM (2001) Standard practice for preparing rock core specimens and determining dimension and shape tolerances. Am Soc Test Mater; D4543

[4] Haykin S (2009) Neural Networks and Learning Machines, Third Edition, Prentice Hall.

[5] Kohavi R, Quinlan JR (2002) Data mining tasks and methods: Classification: decision-tree discovery. In Handbook of data mining and knowledge discovery. Oxford University Press. 267-276

[6] Chen Y, Yang B, Dong J, Abraham A (2005) Time-series forecasting using flexible neural tree model. Inform sciences 174:219-235

[7] Ojha VK, Abraham A, Snášel V (2017) Ensemble of heterogeneous flexible neural trees using multiobjective genetic programming. Appl Soft Comput. 52, 909-924

[8] Meulenkamp F, Grima MA (1999) Application of neural networks for the prediction of the unconfined compressive strength (UCS) from Equotip hardness. Int J Rock Mech Min Sci 36:29-39

[9] Grima MA, Babuska R. Fuzzy model for the prediction of unconfined compressive strength of rock samples. Int J Rock Mech Min Sci. 1999;36: 339-349

[10] Singh VK, Singh D, Singh TN (2001) Prediction of strength properties of some schistose rocks from petrographic properties using artificial neural networks. Int J Rock Mech Min Sci 38:269-284

[11] Gokceoglu C, Zorlu K (2004) A fuzzy model to predict the uniaxial compressive strength and the modulus of elasticity of a problematic rock. Eng Appl Artif Intel 17(1):61-72

[12] Singh TN, Kanchan R, Saigal K, Verma AK (2004) Prediction of p-wave velocity and anisotropic properties of rock using artificial neural network technique. J Sci Ind Res 63:32-38

[13] Sonmez H, Gokceoglu C, Nefeslioglu HA, Kayabasi A (2006) Estimation of rock modulus: for intact rocks with an artificial neural network and for rock masses with a new empirical equation. Int J Rock Mech Min Sci 43:224-235 
[14] Tiryaki B (2008) Predicting intact rock strength for mechanical excavation using multivariate statistics, artificial neural networks, and regression trees. Eng Geol 99(1):51-60

[15] Zorlu K, Gokceoglu C, Ocakoglu F, Nefeslioglu HA, Acikalin S (2008) Prediction of uniaxial compressive strength of sandstone using petrography-based models. Eng Geol 96:141-158.

[16] Gokceoglu C, Zorlu K, Ceryanc S, Nefeslioglu HA (2009) A comparative study on indirect determination of degree of weathering of granites from some physical and strength parameters by two soft computing techniques. Mater Charact 60:1317-1327

[17] Yilmaz I Yuksek G (2009) Prediction of the strength and elasticity modulus of gypsum using multiple regression, ANN and ANFIS models. Int J Rock Mech Min Sci 46:803-810

[18] Dehghan S, Sattari GH, Chehreh CS, Aliabadi MA (2010) Prediction of uniaxial compressive strength and modulus of elasticity for Travertine samples using regression and artificial neural networks. Min Sci Tech 20:41-46

[19] Rabbani E, Sharif F, Kooliv M, Salooki, Moradzadeh A (2012) Application of neural network technique for prediction of uniaxial compressive strength using reservoir formation properties. Int J Rock Mech Min Sci 56:100-111

[20] Mishra DA, Basu A (2013) Estimation of uniaxial compressive strength of rock materials by index tests using regression analysis and fuzzy inference system. Eng Geol 60:54-68

[21] Yesiloglu-Gultekin N, Gokceoglu C, Sezer EA (2013a) Prediction of uniaxial compressive strength of granitic rocks by various nonlinear tools and comparison of their performances. Int J Rock Mech Min Sci 62:113-122

[22] Yesiloglu-Gultekin N, Sezer EA, Gokceoglu C, Bayhan H (2013b) An application of adaptive neuro fuzzy inference system for estimating the uniaxial compressive strength of certain granitic rocks from their mineral contents. Expert Syst Appl 40:921-928

[23] Armaghani DJ, Hajihassani M, Bejarbaneh BY, Marto A, Mohamad ET (2014) Indirect measure of shale shear strength parameters by means of rock index tests through an optimized artificial neural network. Measurement 55:487-498

[24] Armaghani DJ, Mohamad ET, Momeni E, Narayanasamy MS, Amin MFM (2015) An adaptive neuro-fuzzy inference system for predicting unconfined compressive strength and Young's modulus: a study on Main Range granite. Bull Eng Geol Environ 74:1301-1319

[25] Mishra DA, Srigyan M, Basu A, Rokade PJ (2015) Soft computing methods for estimating the uniaxial compressive strength of intact rock from index tests. Int J Rock Mech Min Sci 80:418-424

[26] Lam HK, Nguyen HT (2012) Computational intelligence and its applications: evolutionary computation, fuzzy logic, neural network and support vector machine techniques. World Scientific.

[27] Rezaee B, Zarandi MF (2010) Data-driven fuzzy modeling for Takagi-Sugeno-Kang fuzzy system. Inform Sciences, 180(2):241-255

[28] Jang JS (1993) ANFIS: adaptive-network-based fuzzy inference system. IEEE T Syst Man Cyb, 23(3):665685

[29] Poli R, Langdon WB, McPhee, NF, Koza, JR (2008) A field guide to genetic programming. Lulu. Com

[30] Storn R, Price K (1997) Differential evolution-a simple and efficient heuristic for global optimization over continuous spaces. J Global Optim 11:341-359

[31] Das S, Suganthan PN (2011) Differential evolution: a survey of the state-of-the-art. IEEE T Evolut Comput 15(1):4-31

[32] Ojha VK, Schiano S, Wu CY, Snášel V, Abraham A (2016) Predictive modeling of die filling of the pharmaceutical granules using the flexible neural tree. Neural Comput Appl

[33] Mishra DA, Basu A (2012) Use of the block punch test to predict the compressive and tensile strengths of rocks. Int J Rock Mech Min Sci 51:119-127 